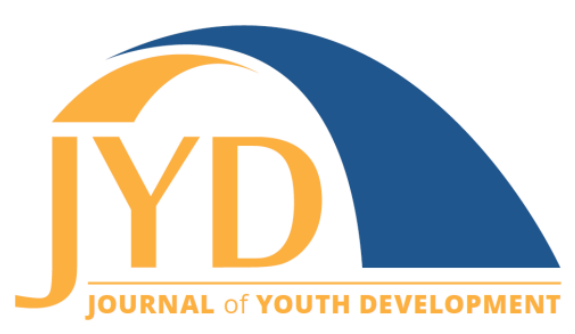

http://jyd. pitt. edu/ | Vol. 14 Issue 2 DOI 10.5195/jyd.2019.679 | ISSN 2325-4017 (online)

\title{
Guiding Principles for Reaching and Engaging Latinx Youth in Youth Development Programs
}

\author{
Fe Moncloa \\ University of California, Agriculture and Natural Resources \\ fxmoncloa@ucanr.edu
}

Nancy Erbstein

University of California, Davis

nerbstein@ucdavis.edu

\section{Aarti Subramaniam}

University of California, Agriculture and Natural Resources

asubramaniam@ucdavis.edu

\section{Claudia Diaz Carrasco}

University of California, Agriculture and Natural Resources

cpdiaz@ucanr.edu

\section{Abstract}

This qualitative study presents practices associated with sustained youth engagement at 13 Latinxserving youth development programs located in 3 California counties: 1 rural, 1 suburban, and 1 urban. Empirical findings reflect 5 key dimensions of practice: (a) integrate extended understandings of positive youth development, (b) support positive ethnic identity development, (c) contend with physiological and social effects of discrimination, (d) respond to the ramifications of economic poverty, and (e) act upon the diversity of local and regional Latinx experience. Study findings translate into guiding principles that youth development programs are encouraged to operationalize based on local interests, needs, and resources.

Key words: immigrant and Latinx youth development, youth programs

(cc) EY New articles in this journal are licensed under a Creative Commons Attribution 4.0 License. This journal is published by the University Library System, University of Pittsburgh and is cosponsored by the University of Pittsburgh Press. The Journal of Youth Development is the official peer-reviewed publication of the National Association of Extension 4-H Agents and the National AfterSchool Association. 


\section{Introduction}

Latinx youth comprise $54 \%$ of California's total youth population (California Department of Education, 2018) and 25\% of youth nationally (U.S. Census Bureau, 2017). However, they have been broadly underserved by large-scale programs intended to promote healthy youth development (Romero, London \& Erbstein, 2010); for example, as of 2013, they represented $33 \%$ of California's 4-H Youth Development Program participants ${ }^{1}$ (University of California 4-H Youth Development Program, 2013). Fulfilling youth development programs' potential to promote well-being requires cultivating and sustaining engagement with a more racially and ethnically diverse population.

In California, Latinx youth reflect multiple national family origins, racial and ethnic backgrounds, migration histories, and home languages. In addition, Latinx families reside in rural, suburban and urban communities and have varied household incomes. However, overall this population tends to experience constrained opportunities and concerning outcomes such as vulnerability indicators for teen birth rate, non-completion of high school, foster care entry, and children living in poverty. Latinx-serving youth development programs that are engaging children and youth in a sustained manner are a valuable source of promising practices. This study presents lessons learned from 13 such organizations based in three California counties.

\section{Background}

A 2014 review of research on youth development program practices associated with high Latinx youth participation and positive outcomes-such as well-being indicators of health, education, social relationship, and community involvement-revealed an emerging area of scholarship that would benefit from further and more nuanced study. Erbstein and Fabionar (2014) systematically reviewed 114 pieces and synthesized research with respect to two guiding questions:

1. What positive youth development program qualities lead to high and sustained participation rates for Latinx youth in the United States?

2. Are there specific attributes of positive youth development programs that lead to positive outcomes for Latinx youth in the United States?

The National Research Council and Institute of Medicine (2002) has identified four dimensions of youth development programs and organizations: conceptual framework, program elements,

\footnotetext{
${ }^{1}$ The limited participation of Latinx youth in the California 4-H program in 2013 was the impetus for this study. By the end of June 2018 , Latinx youth comprised $47 \%$ of the program.
} 
program/organizational structure, and community relationships. While individual studies reviewed rarely considered all these dimensions of practice, the synthesis enabled a comprehensive analysis.

Five cross-cutting areas of practice emerged as salient:

1. Integrate extended understandings of positive youth development that reflect research on the diversity of Latinx and immigrant youth populations.

2. Support positive ethnic identity development.

3. Contend with physiological and social effects of discrimination.

4. Respond to the ramifications of economic poverty.

5. Act upon the diversity of local and regional Latinx experience.

Figure 1 illustrates these five areas of practice.

Figure 1. Practices Associated With Latin@ Youth Engagement in Youth Development Programs (Erbstein \& Fabionar, 2014)

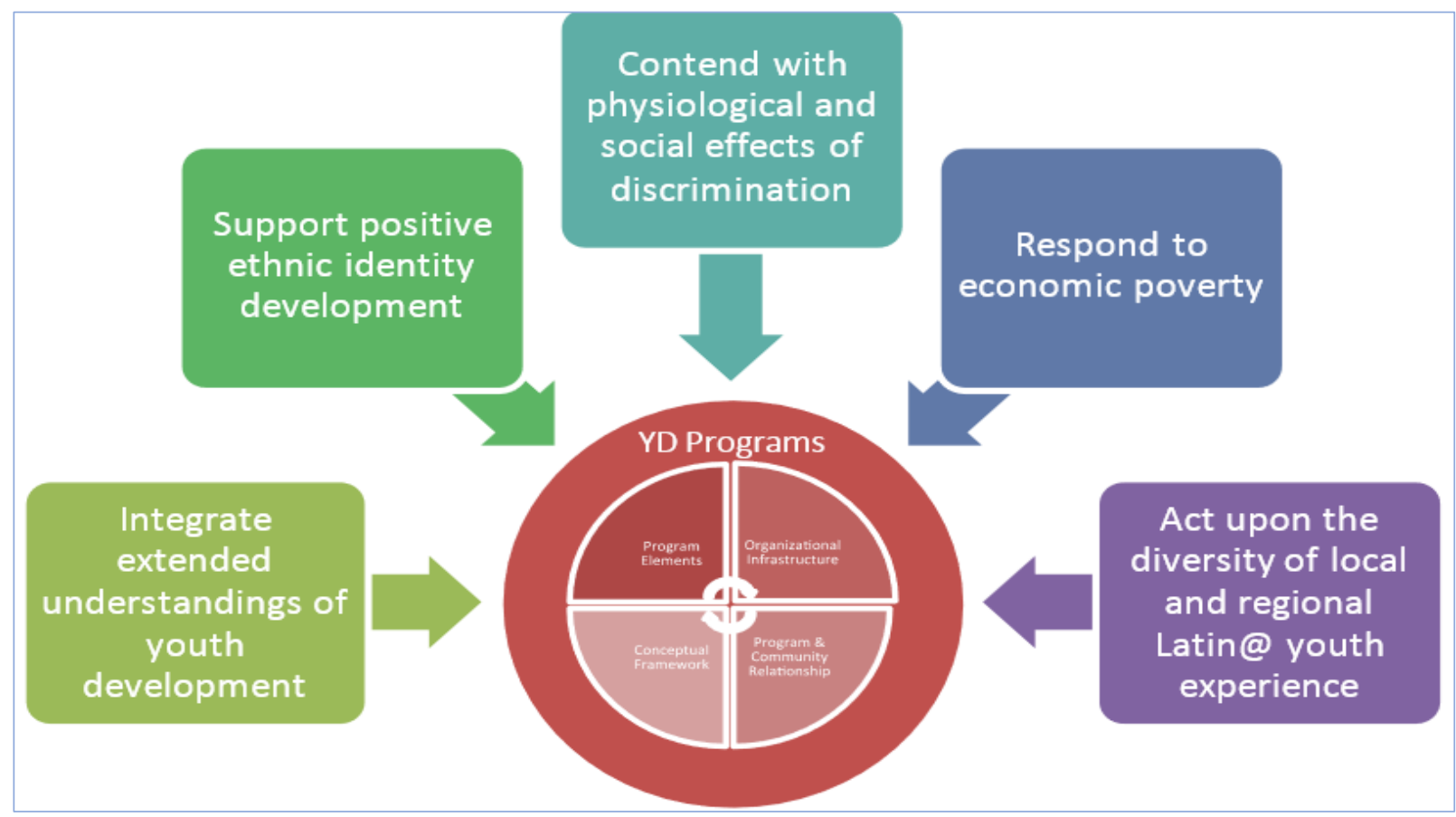

This analysis provided a foundation for empirical research to comprehensively assess program practices associated with Latinx youth engagement across multiple populations and places. 


\section{Methods}

This 2-year qualitative study draws upon interviews with youth-serving professionals and youth served by their programs. The research team included five immigrant Spanish-speaking Latinx members (from Mexico and Peru), an immigrant from India and two individuals of European descent.

\section{Sampling}

Three California counties-one rural, one predominantly urban, and one with both an urban center and peri-urban rural areas-were selected based on geographic diversity, their focus on increasing Latinx youth participation in 4-H programs, and local 4-H Youth Development academics' interest. Potential case study sites were selected through county context mapping, key informant interviews with area Latinx leaders, and youth development leaders and funders to finalize an inventory of research sites, combined with organizational research and key informant interview data to assess program reputation and youth engagement.

Case study sites selected had been in operation for more than one year, served Latinx youth who had been engaged in their programs for at least a year, sustained the majority of young people's participation over time, and had a positive reputation for supporting healthy youth development across multiple key informant interviews. These sites tended to include one or more of three orientations to programming: enrichment, social justice/advocacy, and one-stop wrap-around services. Where more than four or five potential sites were identified, we selected for a variety of organization types (see Table 1 for organizations).

Our study included 18 organization directors and staff-members who participated in interviews. Refer to Table 2 for demographic characteristics. Staff-members invited adolescents who had been involved in their youth program for more than one year to take part in focus groups; a total of 53 Latinx youth participated. One-third of interviewees self-identified as born in Mexico (Zacatecas, Michoacán, Chihuahua, Mexico City, Northern Baja California, and Oaxaca); the others were born in the United States to immigrant parents. A small minority identified as members of indigenous communities (Mixtec and Otomi). Most of these young people were bilingual in Spanish or Mixtec. Participants ranged in age from 11 to 19 years old with an average age of 15 . 
Journal of Youth Development | http://jyd.pitt.edu/ | Vol. 14 Issue 2 DOI 10.5195/jyd.2019.679

Principles for Engaging Latinx Youth in Programs

Table 1. Names and Type of Organizations

\begin{tabular}{|l|l|l|}
\hline County & Organization name (Pseudonym) & Organization type \\
\hline Merced & Just Media & Social Justice/Advocacy \\
\hline Santa Clara & Social Justice Advocates & Social Justice/Advocacy \\
\hline Riverside & Wellness in Community & Social Justice/Advocacy \\
\hline Riverside & Design Your City & Social Justice/Advocacy \\
\hline Riverside & Building Cultural Identity & Social Justice/Advocacy \\
\hline Santa Clara & Comprehensive Support & Social Justice and One-stop \\
\hline Santa Clara & Urban Art Promotion & Enrichment \\
\hline Santa Clara & Youth and Family Community Center & Enrichment \\
\hline Santa Clara & Youth Afterschool & Enrichment \\
\hline Riverside & Mentoring Youth of Color & Enrichment \\
\hline Riverside & Expanded Learning for All & Enrichment \\
\hline Merced & Pueblos Indigenas & Enrichment and One-stop \\
\hline Merced & United for Youth & Enrichment and One-stop \\
\hline
\end{tabular}

Table 2. Staff Interviewee Demographics

\begin{tabular}{|l|l|}
\hline Demographic & Characteristics \\
\hline Ethnicity & $\begin{array}{l}\text { Latinx from Mexico (15) } \\
\text { Mixteco (1) } \\
\text { Latinx-Asian (1) } \\
\text { Latinx from Guatemala (1) }\end{array}$ \\
\hline Gender & $\begin{array}{l}\text { Female (9) } \\
\text { Male (9) }\end{array}$ \\
\hline Age range & Early 20s to late 30s \\
\hline
\end{tabular}




\section{Case Study Data Collection}

All data collection protocols were approved by the University of California Davis Institutional Review Board. Data collection included organizational documents reflecting their missions and activities, in-person semi-structured interviews with organizational leaders and staff-members, and focus groups with youth program participants and observations. Interviews and focus groups sought to understand the guiding philosophy of organizations and the strategies and challenges for recruiting, engaging, and sustaining the participation of Latinx youth in youth programs. All interviews were conducted in English, with some use of Spanish, digitally recorded and transcribed verbatim. Before and after all interviews, researchers conducted and documented informal observations. County-based and full team group discussions about the data set were also documented in memos for analysis.

\section{Data Analysis}

This study employed NVIVO 11 to systematically analyze this qualitative dataset (see Table 3 for analysis process). After each of the three cycles of coding the team achieved an inter-rater reliability rate of $87 \%$ (Saldaña, 2009). Triangulation occurred across data sources and data analysis (Patton, 1999). 
Table 3. Data Analysis Phases

\begin{tabular}{|c|c|}
\hline Data analysis phase & Description \\
\hline $\begin{array}{l}\text { Coding cycle 1: } \\
\text { A priori nodes }\end{array}$ & $\begin{array}{l}\text { Case construction via coding of key case characteristics. Broad coding using } \\
\text { a priori nodes based on literature review findings (Erbstein \& Fabionar, } \\
\text { 2014). }\end{array}$ \\
\hline Interrater reliability & $\begin{array}{l}\text { One campus-based researcher coded all interviews; county-based } \\
\text { researchers coded subsets of interviews independently. Inter-rater reliability } \\
\text { was conducted periodically and differences resolved via discussion. }\end{array}$ \\
\hline $\begin{array}{l}\text { Coding cycle 2: } \\
\text { Refined coding }\end{array}$ & $\begin{array}{l}\text { Grounded analysis (Charmaz, 2006; Strauss \& Corbin, 1998) to refine coding } \\
\text { based on whether and how programs: (i) supported ethnic and other } \\
\text { identity development; (ii) tailored efforts to individual and family needs; (iii) } \\
\text { were aware of the forces of discrimination; (iv) addressed poverty; (v) had } \\
\text { an integrated approach to youth development. } \\
\text { Reviewed uncoded data to assess need for additional nodes. } \\
\text { Integrated analysis with respect to organizations' (i) conceptual frameworks, } \\
\text { (ii) organization infrastructure, (iii) program elements, and (iv) community } \\
\text { relationships. }\end{array}$ \\
\hline $\begin{array}{l}\text { Analysis phase 1: } \\
\text { Potential key practice } \\
\text { identification }\end{array}$ & $\begin{array}{l}\text { Identified potential key practices based on the magnitude of nodes (number } \\
\text { of organizations where a practice was featured), as well as prominence of } \\
\text { the concept (how much it was described or articulated). }\end{array}$ \\
\hline $\begin{array}{l}\text { Analysis phase 2: } \\
\text { Key practices } \\
\text { confirmation }\end{array}$ & $\begin{array}{l}\text { Identified practices pursued by at least two organizations. } \\
\text { Reviewed original transcripts and field notes to check findings. } \\
\text { Each practice discussed and agreed upon by full team. } \\
\text { Analytical memos were coded and analyzed. }\end{array}$ \\
\hline $\begin{array}{l}\text { Coding cycle 3: } \\
\text { Key practices }\end{array}$ & $\begin{array}{l}\text { Key practices were entered into NVIVO } 11 \text { as nodes and data were coded to } \\
\text { them to facilitate case study analysis. }\end{array}$ \\
\hline $\begin{array}{l}\text { Analysis phase } 3: \\
\text { Case studies queries }\end{array}$ & $\begin{array}{l}\text { Explored via queries in NVIVO } 11 \text { for differences in practices by organization } \\
\text { type and perspectives among youth and adults. }\end{array}$ \\
\hline
\end{tabular}




\section{Findings}

While there were some variations in organizational practices by organization type, here we present the practices shared by a majority ${ }^{2}$. Youth program participants and adult staff displayed a high degree of agreement. Young people emphasized appreciation for program elements, while adults described conceptual frameworks and organization infrastructure. Our analyses both confirm the salience of our literature review synthesis (Erbstein \& Fabionar, 2014) and offer nuance grounded in practitioner and youth narratives.

\section{Extended Understanding of Youth Development}

These Latinx youth-serving programs' conceptual underpinnings and practices are consistent with those of mainstream positive youth development exemplars (e.g., Gambone \& Connell, 2004; Lerner et al, 2011). For example, they cultivate youth's strengths and assets, encourage engagement with staff and program activities, foster a sense of social belonging, and offer a broad system of supports. Staff and youth emphasize team-building activities and youth voice to ensure programs reflect youth interests. Organizations support skill development and academic success. Most pursue civic engagement, providing additional leadership development opportunities.

Yet these organizations also incorporate additional dimensions of youth development praxis. Important emphases include youth in relationship with their families, personalization, responsibility to the community and positive ethnic identity development. Participating organizations invest in building trusting relationships with family members and, in some cases, directly supporting families. A staff from Design Your City described their efforts:

The first initial outreach that we wanted to do was to reach the parents, so that the parents knew that there was this new resource that their youth can get involved, and they could also know what we were bringing to the table.

Most organizations then invite caregivers to help orchestrate family cultural events, educate parents on school systems or engage in other ways.

\footnotetext{
${ }^{2}$ Variation in the extent to which practices described were employed across case study organizations will be signaled by the qualifiers "most" (represents at least $85 \%$ of organizations, but not all) and "some" (represents at least $70 \%$ of organizations).
} 
Principles for Engaging Latinx Youth in Programs

Staff also report that environments that mimic the close ties of many Latinx families facilitate youth engagement. A young member from Wellness in Community concurred, noting: "I like how after a while we all become very close like family, so we can trust each other, and if we are having problems we can talk. We have someone to like turn to and talk about it." Youth value close, trusting, familial-feeling relationships with staff-members.

Organizations prioritized authentic relationships between staff and youth that were grounded in care, mutual respect and shared experience. During the program, most staff described opportunities to "hang out" with young people in safe environments, where staff demonstrate they genuinely care about the daily activities of youth by inquiring about their lives and listening to them. Youth described staff as mentors they can talk to about almost everything and as resources for navigating any problems.

Staff-members view it as their responsibility to deeply understand youth participants' needs and address root causes of barriers. For example, as the program coordinator from Mentoring Youth of Color mentioned, organizational staff are responsible for "identifying [student] specific needs because sometimes it's not tutoring, it's just the motivation part." In some cases staff took on roles that have been characterized elsewhere as that of "adult allies" (Erbstein, 2013) and "empowerment agents" (Stanton-Salazar, 2011).

All organizations described helping young people understand the importance of giving back to the community to make a positive change as part of their conceptual framework. Program staff support and encourage young people's intrinsic desire and related skill-building. A staff-member from Building Cultural Identity shared:

I think that that's one of the unique things we see out of our space, that our students have really learned . . . they really take on that responsibility, like "I have to come back to the community and give back to the community, "right? Whether that means 4 years from now or 10, you know, later in life. They need to give back and develop more spaces, support and mentor, empower other people.

The principle of giving back to the community goes beyond community service and includes empowering others to foster social change. A youth from Design Your City illustrated the impact of program participation on his trajectory. 
Principles for Engaging Latinx Youth in Programs

From meeting staff and learning about land use planning and community and regional development and . . . participat[ing] in

policies, I became extremely just amazed and in love with the topics. So, Design Your City really just set my goals and inspired me to . . go beyond what I thought I was capable of doing. And because of that I'm . . . double majoring in community development and political science. So, I can go back to my community and implement that policy to create a better sense of community . . . more sustainable infrastructure and equitable land use for residents.

Social justice youth development organizations in particular emphasize helping participants understand the root causes of inequalities that limit opportunity for particular populations and places as an important aspect of healthy development. Equally important, they strengthen participants' capacity to promote transformative social change based on their unique insights and knowledge. A staff from Building Cultural Identity observed:

So what you see with a lot of our students now is that they are able to understand our conditions in our community from a very critical lens. So they can understand it from race, class, gender. They can break it down, you know, on sexual orientation . . . they have the understanding that we live in communities that are a result of . . . systems. So we've been able to build that through our programming.

Efforts support Latinx youth's development by promoting identification of root causes of issues and collective action that addresses systemic social change. Finally, an emphasis on positive ethnic identity development plays out in multiple ways that are described in the following section.

\section{Support Positive Ethnic and Intersectional Identity Development}

Adolescence is a particularly important period of ethnic identity development, one of many facets of social identity that is defined as knowledge about and sense of belonging to one's own ethnic group (Phinney, 1989; Spencer, Swanson \& Harpalini, 2015). Our findings underscore the importance of environments that cultivate a positive sense of Latinx ethnic and cultural identity. 
These organizations provide safe spaces for youth who experience discrimination and negative messages based on their ethnic backgrounds and/or real or perceived immigration status (as well as, in some cases, other intersecting dimensions of their identities). A staff member from Pueblos Indigenas mentioned: "It comes to a point where even young people want to stay away with who they are. They don't want to learn anything about their culture, anything about their language [due to historical and current discrimination]." Discussion of the experiences of indigenous Mexican youth underscores the complexity and multi-layered nature of Latinx ethnic identity, including the importance of examining intra-ethnic relationships.

Staff support identity development in part by encouraging and supporting youth to reach for their goals. A staff member from Just Media stated:

I feel . . . it's just so hard. After so many years where you're told that you can't do it because of what you look like or who you are. ... I think the simple fact that we're telling them, "I believe in you and I know you're going to succeed." It's not like, "I know you can." No. "I know you will. Like, you will do it." And we're going to be there. .. . And we're making sure that each and every single one of our students graduates high school, goes on to a higher education. Like, we make sure that happens.

A youth participant from Pueblos Indigenas added:

Once you own your culture, nobody can stop you. You're like, "Oh, yeah, I'm Mexican and I'm going to be here. I'm going to take this role. . . ." But if you're confused about who you are and where you come from and your roots, you don't have that selfesteem anymore to join or to participate in much.

One young person from Building Cultural Identity expressed: "This is a place for us to express ourselves, and that's also a way of healing." Healing from discrimination and adverse social contexts is highlighted as an important aspect of ethnic identity development, as is youth knowing and owning their culture(s).

These programs also offer a safe space to explore ethnicity as it intersects with other aspects of identity, such as gender and sexual orientation, and to name challenges and build capacities to address them. A young person from Building Cultural Identity explained: 
Principles for Engaging Latinx Youth in Programs

We talk about just different issues: what it means to be a woman of color here in the [regional] Valley, here in this country, what are some of the things that we face, and how do we deal with those things . . the micro-aggressions that we face every day, and it's sort of putting a name to something that we've always felt.

Comfort using a home language and fun programs reinforced ethnic identity development for sustained participation. A staff-member from Building Cultural Identity shared: "They want to have fun, so we try to have ... fun shows. We'll do field trips. We'll take them to . . . Chicano Park or, you know, different places out in the community."

Latinx youth ethnic and intersectional identity development are cultivated in safe spaces where staff build meaningful, mentoring relationships, foster a sense of pride and belonging in their ethnic/cultural background, and engage in conversations and other practices to promote healing from discrimination. Other important strategies include using youths' home language(s) and having fun at culturally-relevant events and places in the community.

\section{Contend With Physiological Effects of Discrimination}

Increasingly research is revealing the physiological impacts of chronic stress and disproportionately negative environmental exposures that are associated with poverty and ethnic discrimination (Edwards and Romero, 2008). In general, organizations responded explicitly to these stressors, albeit in various ways. Some organizations provide wrap-around services to address youth and family physical and mental health challenges. Others emphasize helping young people see themselves as change agents and proactively address root causes and conditions that cause stress and poor health.

In this context, Latinx youth development organizations prioritize hiring individuals with an understanding of historical and current community dynamics that youth and families view as approachable. The director of Urban Art Promotion described the value of staff who share experiences with youth:

There is a challenge there in just finding the people with the right knowledge to fit the right schedule . . many of them have a connection to the youth here and their stories. So, I know that our program assistant was raised here . . . this is his neighborhood . . 
Principles for Engaging Latinx Youth in Programs

. Well he understands his neighborhood, and he really cares for this neighborhood. So that's an added bonus to having him.

Most staff-members had experienced immigration, poverty and racism. A practitioner from Just Media illustrates the significance of this shared experience for relationship building.

They have to hear it from someone who looks like them, someone who they can identify with . . . these young folks are trying to reach out to people who look like them because there's not a lot of mentors and . . role models here in the community who have that. You know... . we only have a few groups of young adults, who they can say, "I look like them. They're doing something really big in their life. That means I can, too."

Organizations privileged hiring staff who understand Latinx youth conditions and share at least some dimensions of lived experience, in order to facilitate relationship-building and support youth to contend with the physiological effects of discrimination.

\section{Respond to Economic Poverty}

California's Latinx youth and families reflect a diversity of socio-economic backgrounds. However, economic poverty is widespread in the United States, with 1 in 3 Latinx children growing up in households with incomes below the federal poverty line (Koball and Jiang, 2018). Each participating organization serves areas with relatively high concentrations of low-income households. All embody a strong, publicized commitment to ensuring full access to their resources, regardless of socio-economic status. This is reflected in efforts to remove economic and transportation barriers to participation, as well as in flexible policies and practices to quickly and respectfully address unmet basic needs.

Most organizations offer referral services to youth and families for counseling or access to information on housing resources. Some organizations offer comprehensive services for families, such as a food pantry during after-school pickup, clothing exchanges, and English language classes for adults. A Youth and Family Community Center staff-member noted:

We never want to close the door on anyone. We always have an open-door policy, and ... we always want to make sure that we keep our students. If it's a financial hardship, we don't want to push them away. We'll do whatever it takes to help them. And, you know, if it means waiving their fees, based on their case, then, yeah, we will go ahead and work on that, child by child. 
Principles for Engaging Latinx Youth in Programs

These organizations not only provide resources but create an environment in which young people do not experience a sense of exclusion or embarrassment. Leaders indicate they will not offer a program when they do not have sufficient funds to offer them free if necessary. Staff members speak privately with youth and family members about their needs for resources or referrals.

\section{Act Upon the Diversity of Local and Regional Latinx Youth Experience}

Across and within counties Latinx youth are a diverse population. They reflect varying immigration histories, ranging from historical family residence in their regions that precedes California statehood to recent arrival. Youth and their families have roots in multiple Mexican states, as well as Central and South American countries and embody various racial, cultural and linguistic backgrounds.

Latinx youth expressed feeling supported by organizations that encourage mutual learning and home language use along with English. Most staff-members speak at least two languages (Spanish and English), which facilitates conversation, relationship-building, and youth participation. In organizations that intentionally engage young people from Mexican indigenous populations, staff speak Mixtec, Trique, or Zapotec as well. In cases where staff do not speak youths' language(s) or youth do not all share a common language, young people willingly facilitate interaction and receive positive recognition for this role.

Beyond language, staff-members consider literacy levels and cultural communication practices within their specific community to adapt program activities to include family members. A staff member from Comprehensive Support expressed:

We're also promoting storytelling because we also understand the literacy of some of the families we work with . . . is not, as high. Some of them may ... not be able to read, or may not be confident in reading. It also may not be a cultural practice for them. But storytelling always is, right?

Most staff and youth describe intentional efforts to support Latinx community-building while promoting art and/or organizing cultural events. Such activity was especially important in areas with few such local resources. A staff member from Building Cultural Identity shared:

One of our longest running event has been Día de los Muertos, so it's one of our biggest events now. But they just wanted to create 
Principles for Engaging Latinx Youth in Programs

space for art and culture, especially in the [neighborhood], where

. . . there aren't a lot of opportunities in general for people to

engage in these things.

Building programming that taps and contributes to the specific attributes and resources of local Latinx communities further strengthens relationships with families, networks and institutions and expands opportunities for Latinx youth.

\section{Discussion}

Our analyses suggest that promising Latinx youth-serving organizations build their work on a conceptual foundation that integrates cultural values that are widely shared among the Latinx population; understandings of race, ethnicity, class and immigration as intersectional and impactful; and positive youth development. Their practices are consistent with those identified by Erbstein and Fabionar (2014) and permeate all dimensions of these organizations to sustain Latinx youth participation.

This study embodies several limitations. First, our focus was California, and although we interviewed adults and youth in urban, suburban and rural settings, participants were predominantly youth and adults of Mexican descent. Thus, perspectives discussed here may not reflect those of youth professionals or youth from other Latinx subgroups in other regions of the United States. Each of these locales was home to large concentrations of Latinx residents, so organizational practices might differ when this is not the case. In addition, by focusing solely on program participants, we do not capture the perspectives of youth who have opted not to engage with these organizations.

Nonetheless, we believe these findings suggest steps that we encourage youth development programs to operationalize in ways that reflect local interests, needs and resources. These include:

- Develop relationships and collaborate with Latinx communities to conduct an assetbased community context map (Erbstein, Moncloa, Olagundoye, Diaz Carrasco, \& Hill, 2017).

- Build an organizational culture that normalizes cultural responsiveness and affirms and builds on Latinx youth and families' cultural and social capital.

- Sustain organizational dialogue to assess strengths and challenges vis-à-vis study findings and develop specific implementation strategies. For example, consider adopting 
hiring practices that give weight to candidates' Latinx community networks and shared experiences with youth participants (Moncloa et al, 2018).

Further analyses of the data set presented here will examine whether and how context matters across the three locales, as well as differences across organization types and among youth and adults. Additional research is also required to tease out relationships between specific practices - or combinations thereof-and Latinx youth outcomes, as well as the influence of local and regional contexts on Latinx-serving youth organizations practices and their impacts.

\section{Acknowledgments}

This project was supported by the University of California, Division of Agriculture and Natural Resources (UC ANR). We acknowledge the significant contribution of Stacy Olagundoye, Claudia Damiani Fontana, Yolva Gil, Russ Hill, and Jose Campos in data collection and analysis.

\section{References}

California Department of Education (2018). 2017-18 Enrollment by ethnicity and grade [Data file]. Retrieved from https://dq.cde.ca.gov/dataquest/dqcensus/EnrEthGrd.aspx?cds=00\&agglevel=state\&year=201718

Charmaz, K. (2006). Constructing grounded theory: A practical guide through qualitative analysis. Thousand Oaks, CA: Sage Publications.

Edwards, L. M., \& Romero, A. J. (2008). Coping with discrimination among Mexican descent adolescents. Hispanic Journal of Behavioral Sciences, 30(1), 24-39. doi:10.1177/0739986307311431

Erbstein, N. (2013). Engaging underrepresented youth populations in community youth development: Tapping social capital as a critical resource. New Directions for Youth Development, 2013(138), 109-124. doi:10.1002/yd.20061

Erbstein, N., \& Fabionar, J. (2014). Latin@ youth participation in youth development programs. Davis: University of California Division of Agriculture and Natural Resources. Retrieved from http://cesantaclara.ucanr.edu/files/261436.pdf

Erbstein, N., Moncloa, F., Olagundoye, S. S., Diaz Carrasco, C., \& Hill, R. (2017). Engaging Latino communities from the ground up: Three tools. Journal of Extension, 55(4). Retrieved from https://joe.org/joe/2017august/tt3.php 
Journal of Youth Development | http://jyd.pitt.edu/ | Vol. 14 Issue 2 DOI 10.5195/jyd.2019.679

Principles for Engaging Latinx Youth in Programs

Gambone, M. A., \& Connell, J. P. (2004). The community action framework for youth development. Prevention Researcher, 11(2), 17-20.

Koball, H., \& Jiang, Y. (2018). Basic facts about low-income children: Children under 18 years, 2016. New York, NY: National Center for Children in Poverty, Columbia University Mailman School of Public Health. Retrieved from http://www.nccp.org/publications/pub_1194.html

Lerner, R. M., Lerner, J. V, Lewin-Bizan, S., Bowers, E. P., Boyd, M. J., Mueller, M. K., . . Napolitano, C. M. (2011). Positive youth development: Processes, programs, and problematics. Journal of Youth Development, 6(3): 40-64. doi:10.5195/jyd.2011.174

Moncloa, F; Horrillo, S.; Diaz-Carrasco, C.; Espinoza, D.; Hill, R.; Soule, K. (2018). Using a translational process to apply Latino youth development research findings in practice. Journal of Extension, 56(6). Retrieved from https://joe.org/joe/2018october/pdf/JOE_v56_6iw3.pdf

National Research Council and Institute of Medicine. (2002). Community programs to promote youth development. Washington, DC: The National Academies Press. doi:10.17226/1022

Patton, M. (2002). Qualitative research and evaluation methods. Thousand Oaks, CA: Sage.

Phinney, J. S. (1989). Stages of ethnic identity development in minority group adolescents. The Journal of Early Adolescence, 9(1-2), 34-49. doi:10.177/0272431689091004

Romero, M., London, J., \& Erbstein, N. (2010). Opportunities and challenges for youth civic engagement. Healthy Youth/Healthy Regions working paper. Davis: University of California, Davis, Center for Regional Change. Retrieved from https://regionalchange.ucdavis.edu/sites/g/files/dgvnsk986/files/inline-

files/Youth_Civic_Engagement.pdf

Saldaña, J. (2009). The coding manual for qualitative researchers. Thousand Oaks, CA: Sage Publications.

Spencer, M. B., Swanson, D. P. \& Harpalani, V. (2015). Conceptualizing the self: Contributions of normative human processes, diverse contexts and social opportunity. In M. Lamb, C. G. Coll, \& R. Lerner (Eds.), Handbook of child psychology and developmental science (pp. 750-793). New York: John Wiley \& Sons.

Stanton-Salazar, R. D. (2011). A social capital framework for the study of institutional agents and their role in the empowerment of low-status students and youth. Youth and Society, 43(3), 10661109. doi: $10.1177 / 0044118 \times 10382877$

Strauss, A., \& Corbin, J. (1998). Basics of qualitative research: Techniques and procedures for developing grounded theory. Thousand Oaks, CA: Sage.

University of California 4-H Youth Development Program (2013). Club ethnicity and gender (youth): By state 2012-2013 [Data file]. Retrieved from https://www.4honline.com/Manager/Report/Management.aspx 
Journal of Youth Development | http://jyd.pitt.edu/ | Vol. 14 Issue 2 DOI 10.5195/jyd.2019.679

Principles for Engaging Latinx Youth in Programs

U.S. Census Bureau. (2017). Hispanic heritage month 2017. (Profile America facts for features: CB-17FF.17). Retrieved from https://www.census.gov/content/dam/Census/newsroom/facts-forfeatures/2017/cb17-ff17.pdf 